\title{
AGIALIA ARENARIA MULS. IN NEW ENGLAND, WITH LOCAL RECORDS FOR OTHER SPECIES ${ }^{1}$
}

\section{By P. J. Darlington, Jr.}

On Apr. 4, 1925, the writer took over three hundred specimens of the European Aegialia arenaria Muls. crawling on the sun-heated sand of the dunes and, especially, of the beach near Ipswich, Mass., where it was evidently thoroughly established. In general form this species resembles $A$. opifex Horn, but is stouter and much larger, about five $\mathrm{mm}$. in length. It may be at once distinguished from all our previously known species by its virtually impunctate pronotum and greatly reduced inner wings, which are not over half the length of the elytra and which are thin and unsuited for flight. Later in the season, notably May 22,1926 , it was found on the sand more sparingly, and was taken under deeply buried logs a little above tide line. The species was more common on the beach proper than on the adjacent higher dunes, while the exact opposite seems to be true of the functionally winged $A$. opifex, a species which has been taken in numbers at the same locality in May, but not at all in April. The first difference may be explained as a specific ethological preference or by the fact that the awkward, flightless arenaria is blown off the heights which its more active relative easily attains The ethological explanation is the more satisfactory, for all our other New England species range inland, while this is apparently unwilling or unable to leave the coast. Arenaria is, however, frequently seen rolling along the sand before the wind, and is occasionally blown into the ocean and washed into the local drift.

Whether this species, now locally so common, is introduced or native it is impossible to say at present, but it is difficult to see how a flightless species of its habits could have crossed the Atlantic to such a comparatively remote point as Ipswich. The species seems to be quite absent on the beaches near Lynn, which is much nearer Boston than is the region in which it occurs, though I have searched as thoroughly in one place as the other. It seems significant that the range of the species in Europe, the entire northern area and Great Britain, is similar to that of

${ }^{1}$ Contributions from the Entomological Laboratory of the Bussey Institution, Harvard University, No. 284. 
many plants which are known to be native both there and in America, and it is notorious that maritime species are wide ranging. It is not easy to see, however, how our many enthusiastic local collectors, past and present, could have entirely missed the species, though perhaps the facts that the spring flight, so called, is exceptionally early, that the insect is less conspicuous later in the year, and that it is flightless and not apt to straggle into more frequented regions may have contributed to its invisibility. The larva, of course, must inhabit the same region as the adult, and must be buried in the sand to escape the heat of the sun, so that it is even less likely to be discovered or transported than the adult. Several other beetles more or less common at Ipswich are poorly represented in local collections, and the few representatives are usually from localities to the south. If it can be shown that arenaria exists at more northern stations and if it does not turn up further south, we shall be able to see how it at least might have been overlooked in the past. Botanical evidence indicates that, if the species is naturally of transatlantic distribution, it should occur in the Gulf of St. Lawrence region.

The determination of the Mass. specimens depends on comparison with one from Europe in the Museum of Comparative Zoölogy and on reference to the literature. There seems to be no other European species with which the present one could well be confused.

In addition to A.arenaria, five species of the genus occur in New England, one of which appears to be at present unrecorded. A. blanchardi Horn, spissipes Lec., opifex Horn, and rufescens Horn are all found in eastern Mass., while the last two have been taken in central N. H. as well. A single specimen of A. lacustris Lec. was taken at Paris, Me., July 9, 1915, by Mr. C. A. Frost, and has been compared with the type. Another unique, also of lacustris, but leaning a little toward cylindrica Esch., was taken by the writer under a stone in Tuckerman's Ravine, Mt. Washington, N. H., Sept. 10, 1926, at about 4,000 ft. elevation. For the final determination of this specimen I am indebted to $\mathrm{Mr}$. H. C. Fall. The previously known range of lacustris includes Nfld. and Mich. 

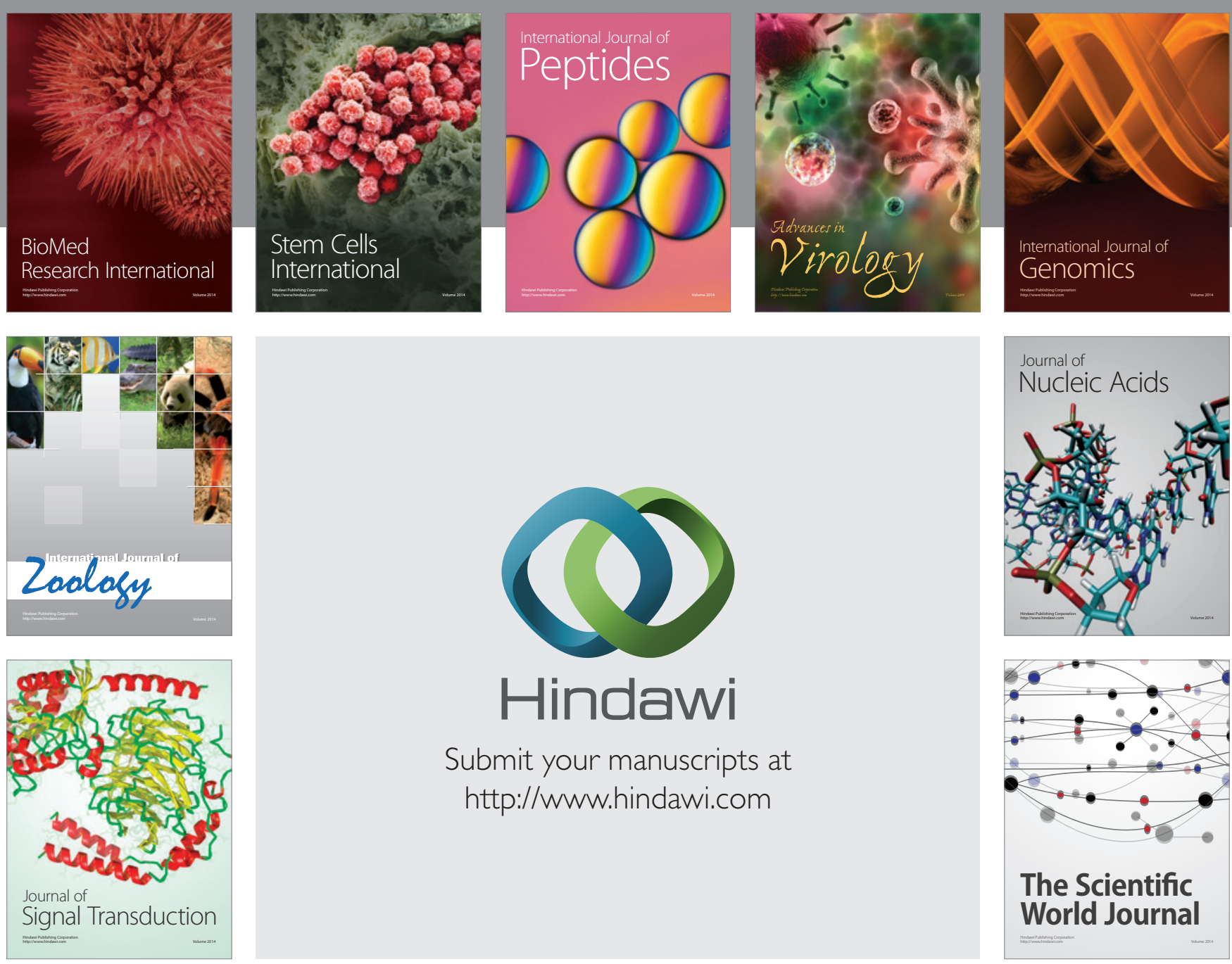

Submit your manuscripts at

http://www.hindawi.com
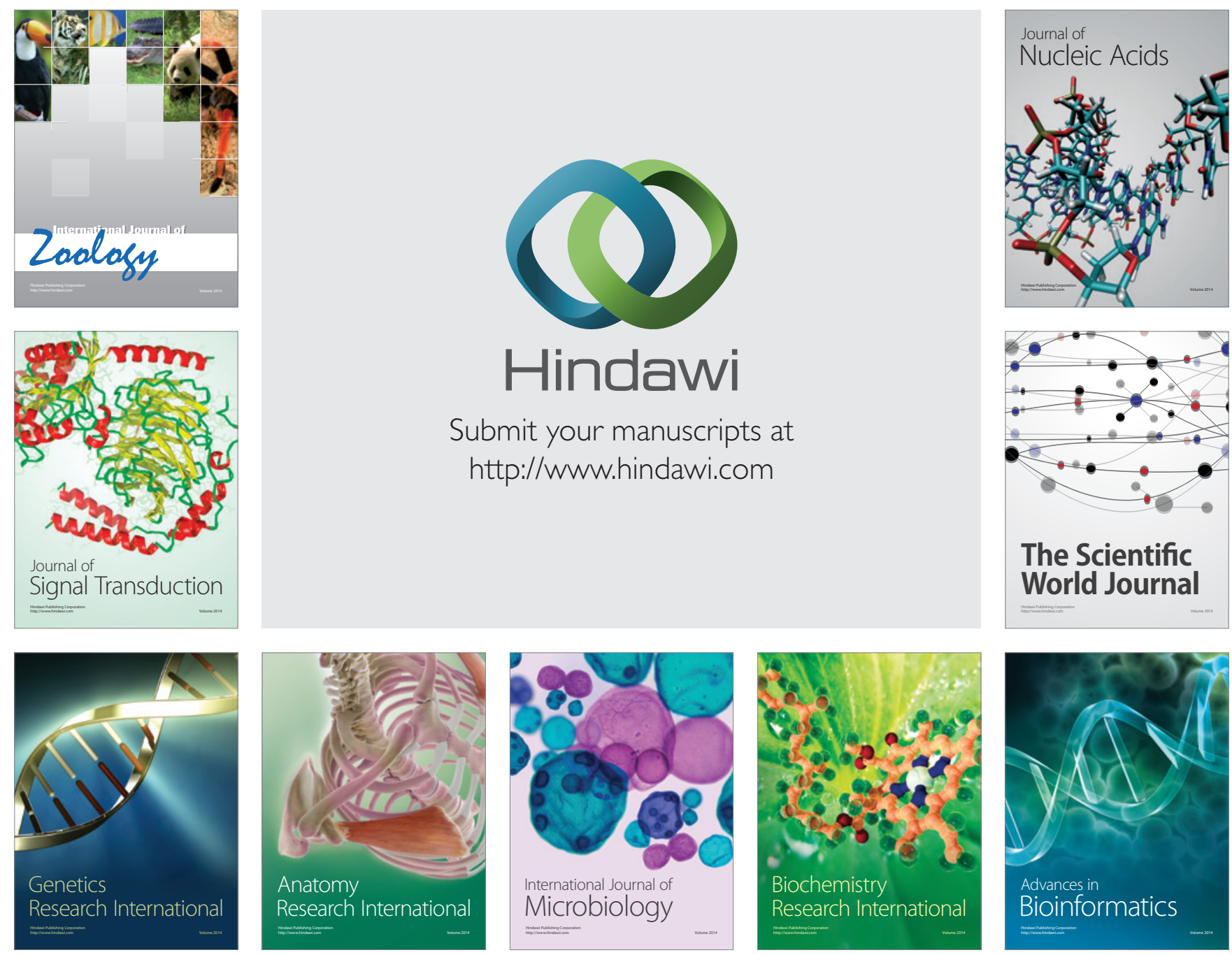

The Scientific World Journal
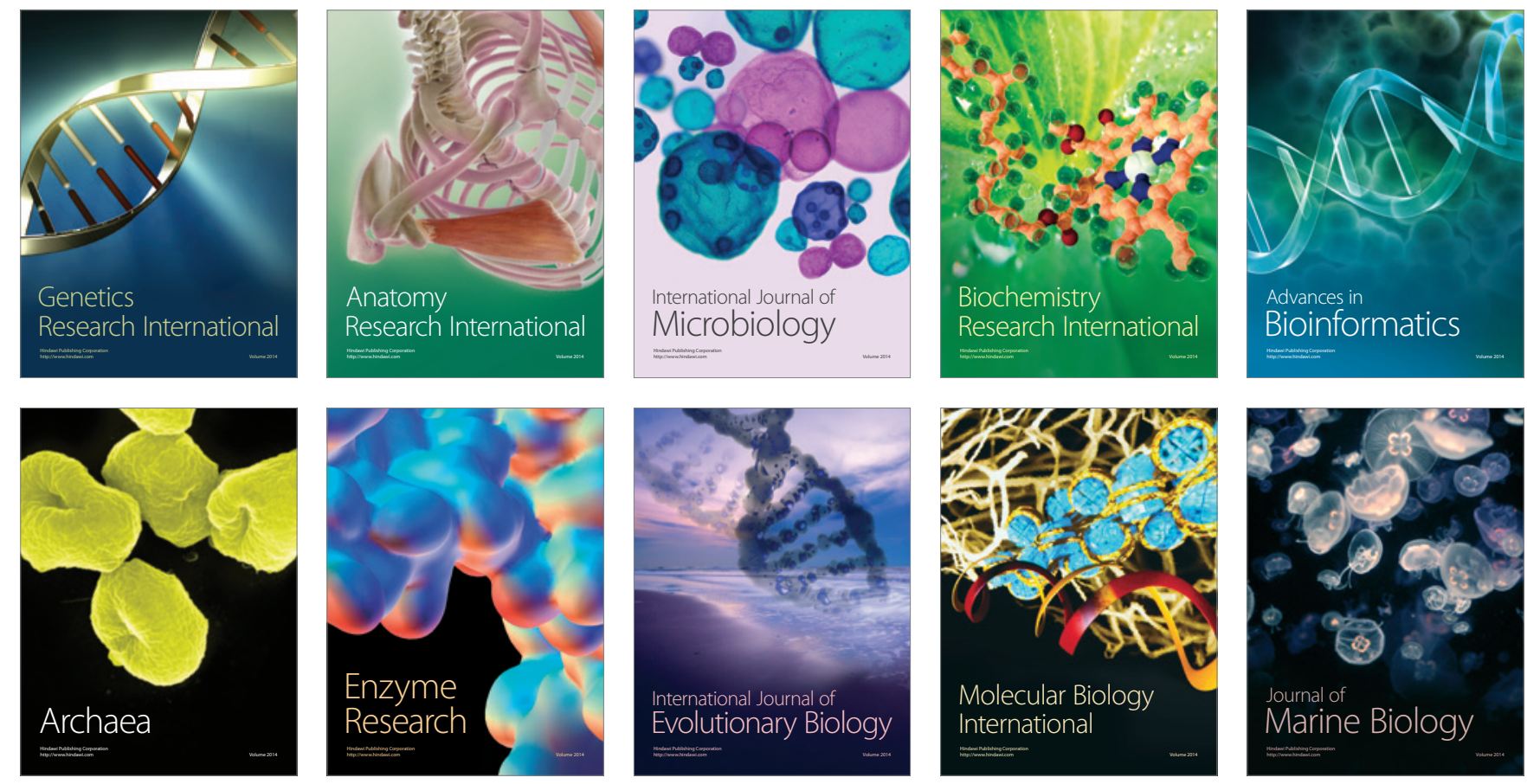